\title{
Comprehensive Evaluation of Distributed Power Quality Based on Improved Entropy Method
}

\author{
Binbin Chen, Ruiming Fang* and Shaotang Xie \\ School of Information Science and Engineering, Huaqiao University, Xiamen, 361021, China \\ ${ }^{*}$ Corresponding author
}

\begin{abstract}
With distributed generation access to the grid, power quality problems become increasingly prominent. These problems can threaten the safe and stable operation of the power grid. This paper establishes a distributed power quality comprehensive evaluation system. The improved entropy method is used to weight the subjective evaluation value and the objective evaluation value, to perform comprehensive evaluation of the power quality of the distributed distribution network. The subjective evaluation is obtained by the improved analytic hierarchy process, and the objective evaluation value is obtained by efficiency evaluation of the distributed power quality data by super efficiency data envelopment analysis. The results show that the improved entropy method considers both subjective and objective factors, resulting in comprehensive evaluation results that are more comprehensive and objective.
\end{abstract}

Keywords-distributed; power quality; improved entropy; subjective evaluation value; objective evaluation value

\section{INTRODUCTION}

Although access of a distributed power supply can improve power and reliability, it will also affect power quality problems of the grid [1].Therefore, when a distributed power supply is connected to the distribution network, it is important to perform a comprehensive assessment of the power quality. Currently, there are many approaches to comprehensive evaluation of power quality, both subjective and objective empowerment. Subjective weighting method mainly assesses the evaluation object based on an expert's own experience, but the use of different experts can cause differences in the results, since the subjective factors are unstable. Common subjective weighting methods include analytic hierarchy process and fuzzy mathematics [2-3]. In [4], the analytic hierarchy process (AHP) was used to evaluate power quality, and many expert opinions were used to determine the weight of each index. Therefore, the power quality evaluation from this method is reasonable and reliable. Commonly used objective weighting methods are: data envelopment analysis, entropy weighting, and gray clustering [5-7]. In[8], the efficiency of the distributed power quality was evaluated by the method of super-efficient data envelopment analysis (DEA), and the weight of the input and output is not taken into account. Objective data can be used to analyze the effectiveness of the decision-making unit. The power quality can be evaluated objectively based on the data of the evaluation index. However, the use of a single method to assess the power distribution index of the active distribution network is limited. To combine subjective evaluation and objective analysis, this study developed an improved entropy method to weight the subjective evaluation value and the objective evaluation value, allowing determination of a comprehensive evaluation of power quality.

\section{EVALUATION INDEX SYSTEM}

Currently, China's power quality indicators include voltage deviation, frequency deviation, three-phase voltage imbalance and eleven other power quality indicators[9].In this study, the distributed power quality evaluation system output index includes voltage deviation, voltage fluctuation, voltage flicker, voltage imbalance, harmonics, frequency deviation, and voltage sagging as the seven power quality indicators. For the input indicators, we consider the distributed power supply parameters, storage capacity, and static var compensator (SVC) capacity, and established a hierarchical structure of the distributed power quality integrated evaluation system as shown in Figure 1.

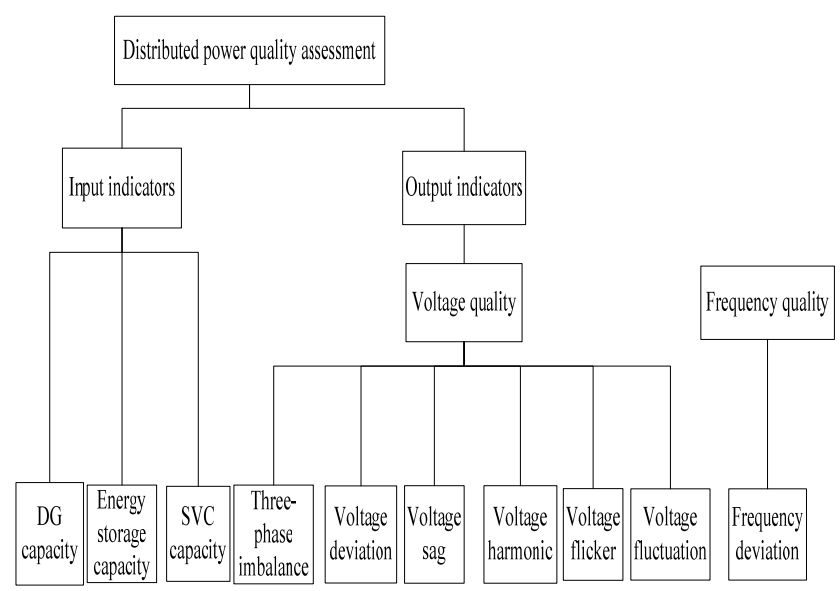

FIGURE I. QUALITY ASSESSMENT SYSTEM OF DISTRIBUTED POWER

\section{IMPROVED ENTROPY METHOD}

After establishing the distributed power quality evaluation index system, the improved entropy method is used to evaluate the power quality. The first need to standardize the index data, then the subjective evaluation value is obtained by the improved AHP, and the objective evaluation value is obtained by the super efficiency DEA algorithm. Finally, the entropy weight method is used to weight the subjective and objective evaluation value, and the comprehensive evaluation value is calculated. The specific algorithm flow chart is shown in Figure 2. 


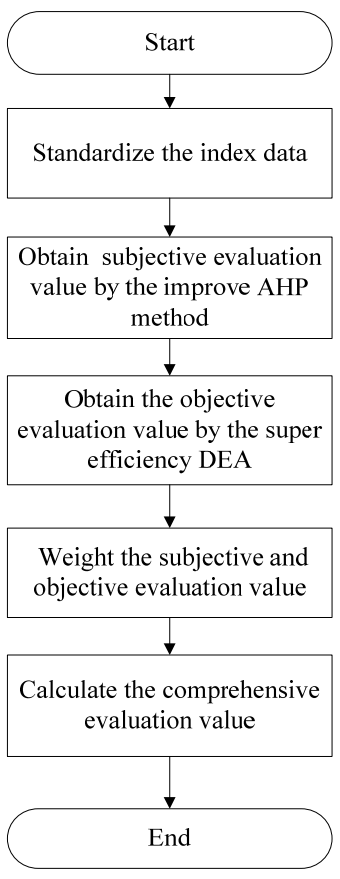

FIGURE II. METHOD OF EVALUATING POWER QUALITY BY IMPROVED ENTROPY METHOD

\section{A. Subjective Evaluation Value}

The subjective evaluation value is the evaluation value obtained by the subjective weighting method. In this study, the subjective evaluation value was obtained by the improved AHP.

In this study, a three scale method was used to assess the importance between the indicators: important, equally important, or not important. This method only requires comparison of the importance between indicators, and the judgment matrix does not need to verify the consistency matrix. The formula of the three-scale method is as follows[10]:

$$
a_{i j}=\left\{\begin{array}{cc}
1 & \mathrm{i} \text { is more important than the } \mathrm{j} \text { indicator } \\
0 & \mathrm{i} \text { is as important as the } \mathrm{j} \text { indicator } \\
-1 & \mathrm{i} \text { is not important than the } \mathrm{j} \text { indicator }
\end{array}\right.
$$

According to the expert opinion obtained from the matrix, the root method is then used to calculate the weight of the indicators:

$$
W_{i}=\frac{\overline{W_{i}}}{\sum_{j=1}^{n} \overline{W_{j}}}
$$

Additionally, $W_{i}$ is the weight of each index; $\overline{W_{i}}$ is the nth root of the product of the $i$ row of $a_{i j}$; and $\overline{W_{j}}$ is the nth root of the product of the $j$ columns of $a_{i j}$.

According to the fuzzy data method, the subjective evaluation value is obtained as follows:

$$
S=\sum_{i=1}^{n} W_{i} D_{i}
$$

$S$ is the subjective evaluation value, where a greater value of $S$ corresponds to better power quality; $W_{i}$ is the weight value; and $D_{i}$ is the value of the data after normalization.

\section{B. Objective Evaluation Value}

The objective evaluation value is the evaluation value obtained by the objective weighting method. In this method, the subjective evaluation value is obtained by the super efficiency DEA algorithm.

DEA is a linear programming mathematical model that uses non-parameters directly to input and output data. DEA is based on the weight of the input and output data in the decision unit as a variable to reach the most favorable decision-making point for a comprehensive evaluation[11]. The super efficiency DEA model effectively improves on the limits of the traditional DEA model, and can distinguish these advantages and disadvantages of DMU. This model is as follows [12]:

$$
\left\{\begin{array}{c}
\text { s.t } \sum_{j=1}^{\min } X_{j} \lambda_{j}+S^{-}=\theta X_{k} \\
\sum_{j=1}^{n} Y_{j} \lambda_{j}-S^{+}=Y \\
\lambda^{-} \geq 0 \\
S^{+} \geq 0
\end{array}\right.
$$

$\theta$ is the efficiency value of the decision unit, $X_{j}$ and $Y_{j}$ are the input index data and the output index data respectively, $\lambda$ is the combination coefficient of DMU.

\section{The Establishment of Evaluation Matrix}

The evaluation matrix includes the subjective and the objective evaluation values of the power quality of each evaluation point. There are $m$ evaluation objects, $n$ evaluation indicators, and the evaluation matrix is:

$$
X=\left(\begin{array}{ccc}
x_{11} & \cdots & x_{1 n} \\
\vdots & \ddots & \vdots \\
x_{m 1} & \cdots & x_{m n}
\end{array}\right)
$$

$x_{m n}$ is the index value of the $m$ evaluation point on the $n$ evaluation index.

For the evaluation index, the subjective evaluation value and the objective evaluation value belong to the benefit type index. For comprehensive evaluation of the calculation, the 
evaluation matrix must be standardized. This standardization is performed as follows:

$$
r_{m n}=\frac{x_{m n}}{\max _{n}\left\{x_{m n}\right\}+\min _{n}\left\{x_{m n}\right\}}
$$

$\max _{n}\left\{x_{m n}\right\}, \min _{n}\left\{x_{m n}\right\}$ is the maximum and minimum value of the power quality evaluation index of all the evaluation sections, and the evaluation matrix is converted into the power quality standard evaluation matrix $r_{m n}$.

\section{The Entropy of the Evaluation Index}

In the evaluation scheme with $m$ evaluation objects and $n$ evaluation indexes, the entropy of the $j$ index is defined as:

$$
\begin{gathered}
H_{j}=-k \sum_{i=1}^{m} f_{i j} \ln f_{i j}, j=1,2, \cdots, n \\
f_{i j}=r_{i j} / \sum_{i=1}^{m} r_{i j}, k=1 / \ln m
\end{gathered}
$$

The traditional entropy weight formula has some limitations. When the entropy ${ }_{j}$ of the index is close to 1 , the entropy values should be similar; however, the results of the traditional entropy method are quite different. In this study, a large positive number $M$ is added to the numerator denominator of the traditional entropy weight formula to correct this problem[13]. The improved entropy formula is as follows:

$$
\omega_{j}=\frac{1-H_{j}+M}{\sum_{j=1}^{n}\left(1-H_{j}+M\right)}
$$

$\omega_{j}$ represents the weight of the ${ }^{j}$ indicator, when ${ }^{j=1}$, the entropy weight for subjective evaluation value, $j=2$, the entropy of the objective evaluation value, ${ }^{0 \leq \omega_{j}} \leq 1$. $M$ for a positive number greater than zero.

The value of $M$ should be based on the actual application of the situation. If the index entropy in the evaluation model is very close to $M$, then $M$ should be made a larger value. If the size of the index entropy in the evaluation model is large, then $M$ should be a smaller value. In general, the smaller the entropy change due to the change in $M$, the better the effect of the correction.

\section{E. Comprehensive Evaluation Value}

According to the entropy weight of the evaluation index and the standard evaluation matrix, the comprehensive evaluation value can be obtained as follows:

$$
V=\omega_{j} \cdot r_{m n}^{T}
$$

$V$ is the comprehensive evaluation of power quality, where a greater value of $V$ indicates better power quality. ${ }{ }_{m n}$ is the standard evaluation matrix.

\section{CASE STUDIES}

In this study, five distributed power supply evaluation points were used as described in [8].The power quality of each

\begin{tabular}{|c|c|c|c|c|c|c|c|c|}
\hline \multirow{2}{*}{$\begin{array}{l}\text { Evalu } \\
\text { ation }\end{array}$} & \multicolumn{2}{|c|}{$\begin{array}{c}\text { input } \\
\text { indicators }\end{array}$} & \multicolumn{6}{|c|}{ Output indicators } \\
\hline & $\begin{array}{c}D G \\
\text { Cap } \\
\text { acity } \\
/ M W\end{array}$ & $\begin{array}{c}S V C \\
/ M v a \\
r\end{array}$ & $\begin{array}{c}\text { Index } \\
1 / \mathrm{Hz}\end{array}$ & $\begin{array}{c}\text { Inde } \\
x \\
2 / \%\end{array}$ & $\begin{array}{c}\text { Inde } \\
x \\
3 / \%\end{array}$ & $\begin{array}{c}\text { Inde } \\
x \\
4 / \%\end{array}$ & $\begin{array}{c}\text { Index } \\
5 / \%\end{array}$ & $\begin{array}{c}\text { Ind } \\
\text { ex } \\
6 / \%\end{array}$ \\
\hline 1 & 40 & 3.0 & 0.122 & 4.80 & 1.33 & 0.54 & 52.44 & 0.83 \\
\hline 2 & 17 & 1.3 & 0.062 & 1.68 & 0.53 & 0.33 & 75.89 & 0.36 \\
\hline 3 & 32 & 2.0 & 0.180 & 4.35 & 1.95 & 0.93 & 3.56 & 1.35 \\
\hline 4 & 42 & 3.2 & 0.177 & 6.33 & 1.37 & 0.84 & 17.30 & 1.74 \\
\hline 5 & 23 & 2.1 & 0.102 & 3.22 & 0.88 & 0.32 & 62.30 & 0.83 \\
\hline
\end{tabular}
evaluation point is shown in Table 1. Output indicators 1-6 are frequency deviation, voltage deviation, voltage fluctuation, voltage flicker, voltage sag, and three-phase unbalance.

TABLE I. DATA FOR POWER QUALITY

\section{A. The Calculation of Objective Evaluation Value}

The efficiency value of the evaluation point is obtained by using the super-efficient DEA model, providing the objective evaluation value. The calculated values are then sorted based on the objective evaluation value of the five evaluation points of power quality. As shown in Table 2 .

TABLE II. THE OBJECTIVE EVALUATION OF POWER QUALITY

\begin{tabular}{cccccc}
\hline $\begin{array}{c}\text { Evaluation } \\
\text { point }\end{array}$ & 1 & 2 & 3 & 4 & 5 \\
\hline $\begin{array}{c}\text { Evaluation } \\
\text { value }\end{array}$ & 0.8868 & 1.9678 & 2.2260 & 0.7731 & 1.1422 \\
\hline
\end{tabular}

\section{B. The Calculation of the Subjective Evaluation Value}

The expert opinion from [14] was used to determine the weight of the power quality indicators in the following order of importance: frequency deviation $>$ voltage deviation $>$ voltage fluctuation $=$ voltage flicker $>$ three-phase unbalance $>$ voltage sag. The three-scale method was used to obtain the weight of the power quality index can be obtained according to equation (2), as shown in Table 3. 
TABLE III. WEIGHT ASSIGNMENT OF INDICATORS

\begin{tabular}{ccccccc}
\hline $\begin{array}{c}\text { Evaluatio } \\
\text { n of } \\
\text { indicators }\end{array}$ & $\begin{array}{c}\text { Index } \\
1\end{array}$ & $\begin{array}{c}\text { Index } \\
2\end{array}$ & $\begin{array}{c}\text { Index } \\
3\end{array}$ & $\begin{array}{c}\text { Index } \\
4\end{array}$ & $\begin{array}{c}\text { Index } \\
5\end{array}$ & $\begin{array}{c}\text { Index } \\
6\end{array}$ \\
\hline & & & & & \\
Weights & $\begin{array}{c}0.329 \\
2\end{array}$ & $\begin{array}{c}0.235 \\
8\end{array}$ & $\begin{array}{c}0.143 \\
0\end{array}$ & $\begin{array}{c}0.143 \\
0\end{array}$ & $\begin{array}{c}0.062 \\
2\end{array}$ & $\begin{array}{c}0.086 \\
8\end{array}$ \\
\hline
\end{tabular}

According to the weight value obtained by the improved AHP method and the evaluation point power quality data, the subjective evaluation value of the power quality of the evaluation point can be obtained using equation (3) as shown in Table 4.

\section{TABLE IV. THE SUBJECTIVE EVALUATION OF POWER QUALITY}

\begin{tabular}{clllll}
\hline $\begin{array}{c}\text { Evaluation } \\
\text { point }\end{array}$ & 1 & 2 & 3 & 4 & 5 \\
\hline $\begin{array}{c}\text { Evaluation } \\
\text { value }\end{array}$ & 0.4708 & 0.9355 & 0.1871 & 0.1383 & 0.6950 \\
\hline
\end{tabular}

\section{The Results of the Improved Power Method}

The entropy weight method is used to weight the subjective evaluation value and the objective evaluation value, and the weight distribution is given in Table 5 . The final evaluation of the power quality is shown in Table 6.

\section{TABLE V. COMPREHENSIVE INDEX WEIGHT DISTRIBUTION}

\begin{tabular}{ccc}
\hline $\begin{array}{c}\text { Comprehensive } \\
\text { assessment of } \\
\text { indicators }\end{array}$ & $\begin{array}{c}\text { Subjective } \\
\text { evaluation } \\
\text { value }\end{array}$ & $\begin{array}{c}\text { Objective } \\
\text { evaluation } \\
\text { value }\end{array}$ \\
\hline Weights & 0.4739 & 0.5261 \\
\hline
\end{tabular}

TABLE VI. COMPREHENSIVE EVALUATION OF POWER QUALITY

\begin{tabular}{clllll}
\hline $\begin{array}{c}\text { Evaluation } \\
\text { point }\end{array}$ & 1 & 2 & 3 & 4 & 5 \\
\hline $\begin{array}{c}\text { Evaluation } \\
\text { value }\end{array}$ & 0.2060 & 0.9024 & 0.5363 & 0.0780 & 0.4414 \\
\hline
\end{tabular}

\section{Results Contrast}

The power quality of each evaluation point obtained by this method is: Evaluation point 2> Evaluation point 3> Evaluation point $5>$ Evaluation point $1>$ Evaluation point 4.

The differences in the results of this method and results from [8] and [4] are evident in the data shown in Table 7. The difference from the results from [8] are due to the sorting of points 2 and 3 . It can be seen from Table 1 that the evaluation point 2 in addition to the voltage sag indicators, the rest of the power quality indicators are better than the evaluation point 3 , since voltage sag are assigned as smaller weight.the evaluation point 2 The power quality data should be better than the evaluation point 3 .Thus, the power quality data of evaluation point 2 should be better than the evaluation point 3 . It is clear that the improved entropy method makes the evaluation point 2 more reasonable before evaluation point 3 . Compared with the previously described analytic hierarchy process [4], evaluation point 3 is different from evaluation points 5 and 1. In [4], evaluation is based on subjective opinion empowerment, and evaluation point 3 is ranked after evaluation points 5 and 1.In this approach, the efficiency value of evaluation point 3 is the highest, so the improved entropy method will evaluate the ranking of 3 before 5 and 1, resulting in evaluation results that are more objective and realistic.

TABLE VII. COMPARISON OF POWER QUALITY COMPREHENSIVE EVALUATION RESULTS

\begin{tabular}{ll}
\hline \multicolumn{1}{c}{ Method } & \multicolumn{1}{c}{ Ranking of evaluation points } \\
\hline Paper[8] method & $3>2>5>1>4$ \\
Paper[4] method & $2>5>1>3>4$ \\
This paper method & $2>3>5>1>4$ \\
\hline
\end{tabular}

\section{CONCLUSION}

Improving the traditional method for the comprehensive evaluation of power quality, this study considered expert opinion and objective data analysis, and evaluated the distributed power quality by using the improved entropy method. In the traditional entropy method, if some of the index entropy values tend to 1 , there may be a large difference between the index entropy values. The improved entropy method effectively overcomes this limitation. The results of theoretical analysis and numerical examples show that the improved entropy method can obtain more comprehensive evaluation results than the single weighting method.

\section{Acknowledgments}

This study was supported in part by the Major Technology Plan Project of Xiamen (3502Z2011008), and Research and Innovation Ability Training Program for Graduate Students of Huaqiao University (1511401001).

\section{REFERENCES}

[1] Shen Xin, Cao Min, "Research on the Influence of Distributed Power Grid for Distribution Network," Transactions of China Electrotechnical Society, vol. 30, No. 1, pp. 348-352, April 2015.

[2] Shen You-xing, Zeng Ming ,Li Yi-jun. "Research on Internal Evaluation of the Service Quality of Power Supply Based on the Improved Fuzzy AHP Method,” Proceedings of International Conference on Management and Service Science, pp. 1-4, April 2009.

[3] XIONG Yi-wang, CHENG Hao-zhong, WANG Hai-qun et al. "Synthetic evaluation of power quality based on improved AHP and probability statistics," Power System Protection and Control. Power System Protection and Control, vol. 13, pp. 49-52, July 2015.

[4] Zhao Xian, Zhou Lixing. “Application of Improved Analytic Hierarchy Process in Comprehensive Evaluation of Power Quality of Distributed Power System,” Electric Power, vol. 47, No. 12, pp. 72-76, December 2014.

[5] Chai Pengfei, Shen Ke, Dong Jin, et al. "Research on synthetic evaluation Method of Power quality Based on Data Envelopment Analysis,” .Electrical Measurement \& Instrumentation, vol. 53, No. 4,pp. 124-129, Feb.2016.

[6] Ouyang Sen, Shi Yili. "Improved entropy method and its application in power quality assessment,” Automation of Electric Power Systems, vol. 37, No. 21, pp. 156-164, Nov. 2013.

[7] Zhou Hui, "a power quality evaluation method based on gray clustering,” Power System Protection and Control, vol. 40, No. 15, pp. 70-74, Aug.2012. 
[8] Fu Xueqian, Liu Guote, Chen Haoyong, etc. "Power quality comprehensive evaluation method for Distributed power," Proceedings of the CSEE, vol. 34, No. 25, pp. 4270-4275, Sep.2014.

[9] WU Chuanlai, YANG Honggeng, ZHANG Yunhong, etc. "Power Quality Comprehensive Evaluation Considering the Indexes' Influence On Weights,” Automation of Electric Power Systems, vol. 25, No. 4,pp.97-102,Aug,2013.

[10] Li Yuanbo, Jiang Tiezheng, Chen Jiajun. [J]. "Multi-objective programming of electric vehicle charging station using super efficiency data envelopment analysis,"Power supply technology, vol. 40, No.4, pp. 849-860, April 2016.

[11] Andersen P,Petersen N C.A procedure for ranking efficient units in data envelopment analysis[J].Management Science,1993,39(10):1261-1264.

[12] WANG Ming-hui, ZHANG Qiao, LING Fei-xiang. “Application of Improved Analytic Hierarchy Process in Performance Evaluation of PPP Project,” Mathematics in Practice and Theory, vol. 41, No.13, pp. 51-55, July 2017.

[13] Zhang Jin-yue, Ren Jie. "Entropy and entropy in the entropy theory of the lack of calculation and correction," Statistics \& Information Forum, vol. 26, No.1, pp.3-5, Jan.2011.

[14] LIU Jun-hua, LUO Long-fu, ZHANG Zhi-wen, et al. “A new method for comprehensive evaluation considering the analysis of sequence stability analysis,” Proceeding of the Chinese Society for Electrical Engineering, vol. 33, No.1, pp. 70-75, Jan.2013. 